\title{
KAJIAN MORFOLOGI SUNGAI LAU BORUS DI KABUPATEN KARO AKIBAT ALIRAN LAHAR DINGIN PASCA ERUPSI GUNUNGAPI SINABUNG TAHUN 2016
}

\author{
Sylvia Aldriani', Dwi Wahyuni Nurwihastuti² \\ 'Alumnus S1 Jurusan Pendidikan Geografi Fakultas Ilmu Sosial Universitas Negeri Medan \\ 2Jurusan Pendidikan Geografi Fakultas Ilmu Sosial Universitas Negeri Medan \\ JI. Willem Iskandar Psr V Medan Estate Medan, 20211 Indonesia \\ Email: sylviaaldriani@gmail.com
}

\begin{abstract}
The research was conducted in the Lau Borus river flow, Karo in 2016. The objectives were to determine the morphology of river flow as a result of lahar flow after the eruption of Sinabung volcano and to investigate the characteristics of Lau Borus River after bypassed cold lava flow. The research population was the Lau Borus river flow in Karo. Data collection techniques were survey techniques and documentary studies. Data processing techniques were descriptive and qualitative. The parameters that used to measure the river morphology changes were the river flow, the high of riverbank, the width of riverbank, the width of the river, and the river gradient. The results show that the river gradient was $2.4 \%$. High of riverbank in the right side of the river was $0.52-2.71 \mathrm{~m}$. Highof riverbank in theleft side of the river was $1.06-3.17 \mathrm{~m}$. The width of riverbank in the right side of the river was 0.3 $46.36 \mathrm{~m}$. The width of riverbank in the left side of the river was $1.08-36.15 \mathrm{~m}$. The velocity of Lau Borus River flow was $3.84 \mathrm{~m} 3 / \mathrm{s}$. The river width was $7.01-156.58 \mathrm{~m}$. Moreover, the characteristics of the upstream are not flowing by lahar flow. The middle of the river was flowing by lahar flow. The downstream of the river was flowing by lahar flow.
\end{abstract}

Keywords: river morphology, lavaflow, Sinabung

\begin{abstract}
Abstrak
Penelitian ini dilaksanakan di aliran Sungai Lau Borus, Kabupaten Karo pada Tahun 2016. Penelitian ini bertujuan untuk mengetahui keadaan morfologi aliran sungai akibat lahar dingin pasca erupsi Gunungapi Sinabung dan mengetahui karakteristik Sungai Lau Borus sesudah dilewati aliran lahar dingin.Populasi dalam penelitian ini adalaha liran Sungai Lau Borus, Kabupaten Karo. Teknik pengumpulan data dengan teknik survey dan teknik studi dokumenter. Teknik pengolahan data secara deskriptif kualitatif. Instrumen yang digunakan untuk mengukur perubahan morfologi sungai yaitu debit aliran sungai, tinggi tebing, lebar tebing, lebar sungai, dan gradien sungai. Gradien sungai adalah 2,4\%. Tinggi tebing sebelah kanan sungai adalah 0,52-2,71 m. Tinggi tebing sungai sebelah kiri adalah 1,06-3,17 m. Lebar tebing sungai sebelah kanan adalah 0,3-46,36 m. Lebar tebing sebelah kiri adalah 1,08 - 36,15 m. Debit Sungai Lau Borus adalah 3,84 m3/s. Lebar sungai adalah 7,01 - 156,58 m. Karakteristik sungai di bagian hulu tidak dialiri oleh aliran lahar dingin, bagian tengah aliran sungai dialiri oleh aliran lahar dingin, bagian hilir dialiri oleh aliran lahar dingin.
\end{abstract}

Kata kunci :Morfologi Sungai, Aliran Lahar Dingin, Sinabung

\section{PENDAHULUAN}

Kenampakan alam di permukaan bumi meliputi wilayah perairan dan daratan. Salah satu kenampakan alam yang meliputi wilayah perairan ialah sungai.
Peraturan Pemerintah Republik Indonesia No. 38 Tahun 2011 mengemukakan bahwa "Sungai adalah alur atau wadah air alami dan/ atau buatan berupa jaringan pengaliran air beserta air di dalamnya, 
mulai dari hulu sampai muara dengan dibatasi kanan dan kiri oleh garis sempadan". Berdasarkan uraian tersebut air sungai berawal dari hulu sungai yang berasal dari mataair di gunung dan bermuara ke laut. Hulu sungai umumnya berasal dari mataair yang berasal dari mataair tersimpan di lereng-lereng gunung. Karakteristik sungai di bagian hulu memiliki debit air yang lebih besar (deras) karena letaknya di lereng yang curam sehingga air mengalir ke bawah mengikuti arah lerengnya. Semakin besar kemiringan lereng sungai maka semakin besar debit air sungai yang mengalir. Proses tersebut menyebabkan terjadinya erosi di tebing sungai yang akan mempengaruhi tinggi tebing, lebar tebing, dan kemiringan sungai.

Salah satu kenampakan alam yang meliputi wilayah daratan ialah gunung. Pulau Sumatera merupakan salah satu pulau yang mempunyai jajaran gunungapi aktif di Indonesia. Scarth, 1994 (dalam Hadmoko, 2015) menyatakan gunungapi merupakan bentukan permukaan bumi berbentuk kerucut yang tersusun dari material erupsi akibat dari terbukanya kerak bumi dan keluarnya magma dari zona panas di bawahnya.

Salah satu gunungapi aktif yang masih mengalami letusan hingga kini yaitu Gunung Sinabung. Gunung Sinabung terletak di Dataran Tinggi Karo sekitar 78,7 $\mathrm{km}$ dari Kota Medan dengan ketinggian 2.460 mdpl. Awalnya Gunung Sinabung merupakan gunungapi strato bertipe $B$ atau sejarah letusannya tidak tercatat dari tahun 1.600-an. Gunung Sinabung yang tercatat letusannya terakhir sekitar 1.200-an kembali mengalami letusan pada tanggal 27 Agustus 2010. Gunungapi Sinabung kembali meletus lagi September 2013 dan berlangsung hingga kini. Erupsi yang terus terjadi menyebabkan Gunungapi Sinabung dinaikkan tipenya menjadi gunungapi tipe A. Letusan Gunungapi Sinabung dikategorikan sebagai tipe letusan freatik yang diikuti jatuhan abu vulkanik menyebar ke timur-tenggara dari puncak
Gunung Sinabung. Gunungapi Sinabung membawa berbagai material vulkanik melalui aliran lahar dingin. Aliran lahar dingin membawa berbagai material vulkanik menuju sungai, perkebunan dan permukiman warga di sekitar kaki Gunung Sinabung.

Aliran lahar dingin menuju ke Sungai Lau Borus yang berhulu di Danau Lau Kawar. Sungai Lau Borus secara administrasi melewati Kecamatan Namanteran, Kecamatan Payung, Kecamatan Simpang Empat, dan Kecamatan Tiganderket. Aliran Sungai Lau Borus membentuk alur berkelok melewati timur-tenggara kaki Gunung Sinabung. Keadaan morfologi sungai dipengaruhi oleh aliran lahar dingin yang mengalir menuju Sungai Lau Borus. Keadaan morfologi Sungai Lau Borus yang dipengaruhi oleh aliran lahar dingin antara lain debit air sungai, lebar sungai, tinggi tebing sungai, lebar tebing sungai, kemiringan sungai. Keadaan tersebut terjadi karena tertutupnya beberapa sumber mataair yang menuju sungai dan hutan yang merupakan daerah resapan air, hutan sebagai penahan erosi terbakar serta beberapa bagian tebing sungai mengalami erosi akibat debit aliran lahar dingin yang bergesekan dengan tebing sungai.

Dampak aliran lahar dingin terhadap Sungai Lau Borus sejak erupsi tahun 2010 hingga kini ialah mempengaruhi keadaan morfologi sungai dan karakteristik sungai. Sisi tebing sungai mengalami penumpukkan material dan erosi yang disebabkan oleh aliran lahar dingin. Lebar sungai yang semakin besar menyebabkan luas penampang sungai semakin besar. Karakteristik sungai di hulu sungai, di tengah sungai dan di hilir sungai berbeda-beda. Beberapa bagian karakteristik sungai tidak terkena dampak aliran lahar dingin sehingga tidak mempengaruhi keadaan morfologi sungai. Hulu sungai merupakan daerah yang tidak terpengaruh aliran lahar dingin karena daerah letusan membelakangi hulu sungai di Danau Lau Kawar. Bagian tengah sungai 
dan hilir sungai terpengaruh aliran lahar dingin yang ditandai dengan penumpukan material hasil erupsi dan erosi yang disebabkan oleh aliran lahar dingin.

Tujuan penelitian ini adalah: (1) Mengetahui morfologi Sungai Lau Borus (a. Debit aliran sungai; b. Tinggi tebing; $c$. Lebar tebing; d. Gradien sungai; e. Lebar sungai) setelah dialiri aliran lahar dingin pasca erupsi Gunungapi Sinabung Tahun 2016; (2) Mengetahui karakteristik Sungai Lau Borus di hulu sungai, tengah sungai, hilir sungai setelah dilewati aliran lahar dingin pasca erupsi Gunungapi Sinabung Tahun 2016.

\section{METODE PENELITIAN \\ Lokasi Penelitian}

Penelitian ini berlokasi di aliran Sungai Lau Borus. Secara administratif Sungai Lau Borus mengalir melewati Kecamatan Namanteran, Kecamatan Payung, Kecamatan Simpang Empat,dan
Kecamatan Tiganderket. Alasan memilih lokasi ini karena Sungai Lau Borus yang berada di Kabupaten Karo merupakan sungai yang pernah dilewati aliran lahar dingin. Sungai Lau Borus yang berhulu di kaki Gunung Sinabung merupakan sungai yang terkena dampak dari lahar dingin seperti tertutupnya mata air, berubahnya debit air, serta berubahnya ukuran tebing.

Berdasarkan hasil pengamatan peneliti yang bersumber dari observasi lapangan dan wawancara dengan beberapa warga di sekitar aliran Sungai Lau Borus mempengaruhi keadaan fisik sungai dan karakteristik sungai. Peneliti juga berdiskusi dengan Dinas Pekerjaan Umum Kabupaten Karo dan BPBD (Badan Penanggulangan Bencana Daerah) Kabupaten Karo mengenai tingkat kerusakan yang diakibatkan banjir lahar. Aliran Sungai Lau Borus dalam penelitian ini disajikan pada Gambar 1.

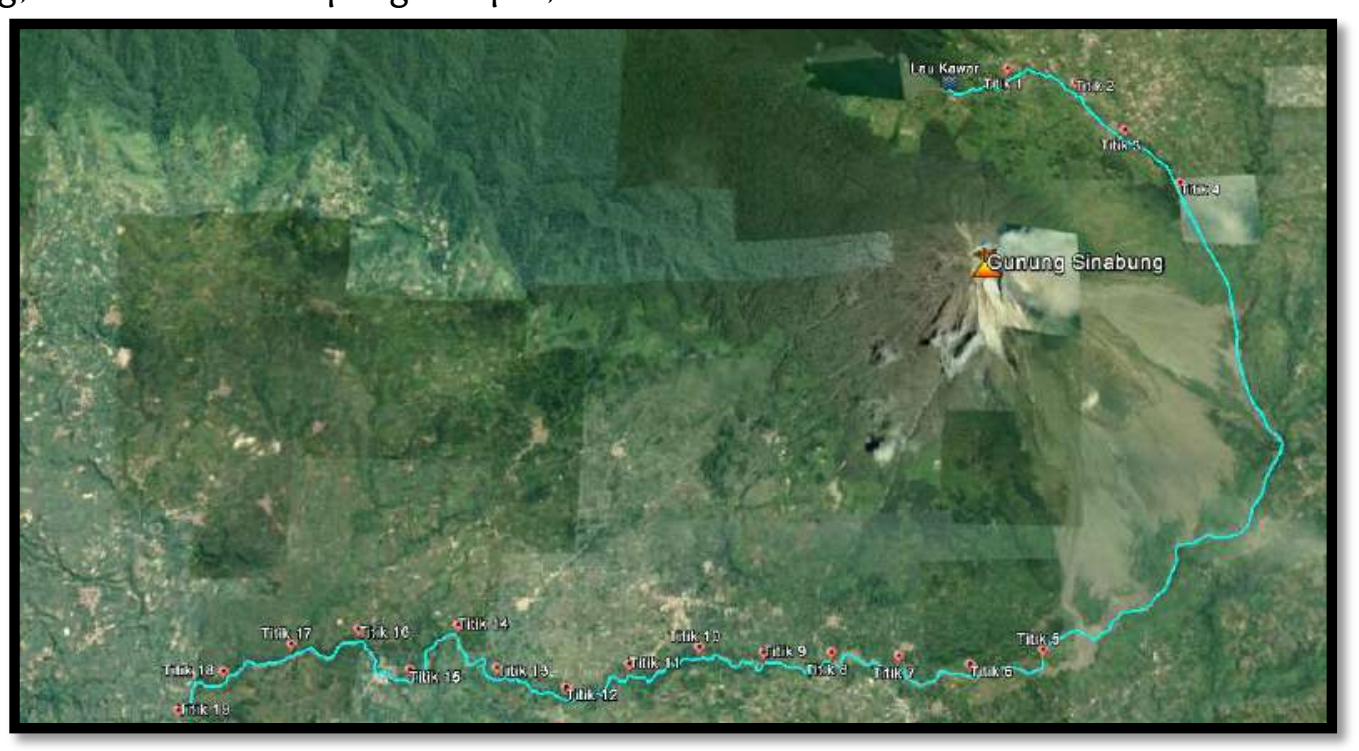

Gambar 1. Aliran Sungai Lau Borus Di Kabupaten Karo (Sumber: Google Earth Pro, 2016)

\section{Populasi dan Sampel}

Populasi penelitian ini adalah aliran Sungai Lau Borus, Kabupaten Karo. Pengambilan sampel melalui teknik purposive sampling tentang keadaan morfologi di Sungai Lau Borus. Purposive sampling merupakan pemilihan subjek sesuai dengan ciri-ciri khusus yang dimiliki oleh sampel (Silalahi, 2009). Sampel dipilih karena dipercaya dapat mewakili satu populasi tertentu. Peneliti memilih sampel berdasarkan aliran sungai yang teraliri aliran lahar dingin dan dapat dijangkau peneliti.

Sampel penelitian ditentukan dengan pengambilan sampel dari hulu sungai yang berada di Danau Lau Kawar hingga ke hilir yang berada di Desa Jandi 
Meriah, Kecamatan Tiga nderket. Sampel yang diambil dipertimbangkan berdasarkan jangkauan peneliti dalam mengambil sampel dan daerah yang paling terkena pengaruh aliran lahar dingin serta izin memasuki daerah zona merah.

Titik penelitian berada di zona merah seperti Desa Kuta Gugung, Desa Sigarang-garang, Desa Simacem, Desa
Gamber, Desa Kuta Tonggal, dan Desa Berastepu yang merupakan desa yang dialiri Sungai Lau Borus. Desa-desa tersebut dilarang masuk oleh pihak kepolisian dan BPBD karena posisi Sungai Lau Borus yang tepat di kaki Gunung Sinabung. Aliran Sungai Lau Borus dalam penelitian ini disajikan pada Gambar 2 yang telah ditentukan titik penelitiannya.

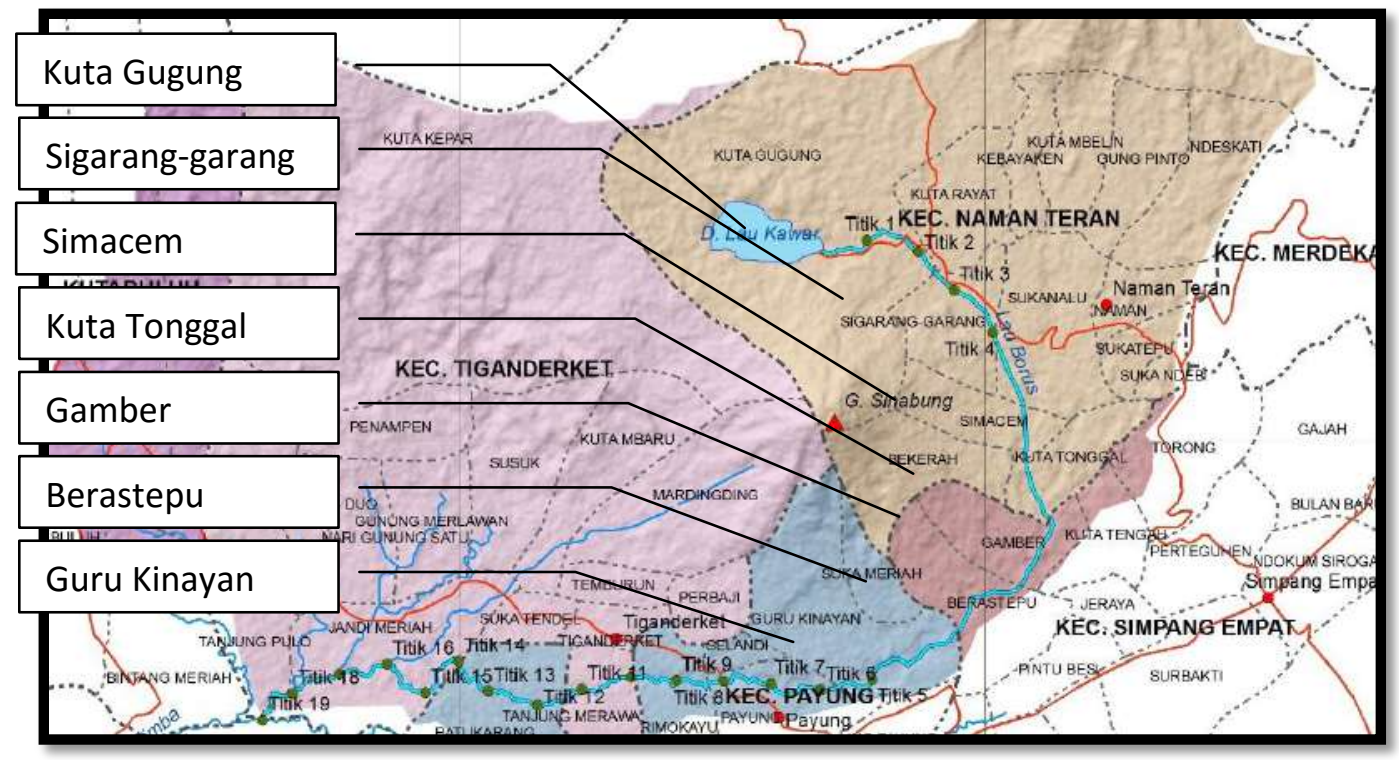

Gambar 2. Titik Sampel Dan Desa Yang Berada di Zona Merah Sinabung (Sumber: Peta DAS Lau Borus, 2016)

Alat

Alat-alat yang digunakan untuk mendukung penelitian ini adalah sebagai berikut:

1. GPS (Global Position System)

2. Meteran

3. Pelampung

4. Kamera Digital

5. ArcMap 10.1

6. Alat Tulis

7. Google Earth Pro

\section{Bahan}

Bahan yang digunakan untuk mendukung penelitian ini adalah sebagai berikut:

1. Peta Administrasi Kabupaten Karo

2. Peta Daerah Aliran Sungai Lau Borus

3. Data Curah Hujan Pos Tiga ancur

4. Peta Penggunaan Lahan Daerah

5. Aliran Sungai Lau Borus
6. Peta Geologi Daerah Aliran Sungai Lau Borus

7. Peta Kelas Lereng Daerah Aliran Sungai Lau Borus

\section{Teknik Pengumpulan Data}

Data yang digunakan pada penelitian ini adalah data primer dan data sekunder yang akan diperoleh dengan menggunakan teknik pengumpulan data, yaitu:

\section{Teknik Observasi}

Observasi dilakukan dengan melakukan pengamatan dan pengukuran langsung ke lokasi penelitian. Pengukuran dilakukan untuk memperoleh data pendukung penelitian berupa data koordinat setiap sampel menggunakan GPS. Data debit air sungai diambil dengan pengukuran menggunakan metode pelampung dengan mengukur jarak 
penampang I \& II, waktu tempuh pelampung, lebar saluran, dan kedalaman sungai. Data tinggi tebing, lebar sungai, dan lebar tebing diambil menggunakan meteran. Data gradien sungai diperoleh dari data elevasi di hulu sungai, hilir sungai, dan panjang sungai. Data yang dikumpulkan antara lain debit aliran sungai, tinggi tebing sungai, lebar tebing sungai, elevasi di hulu sungai, elevasi di hilir sungai, lebar sungai serta data lainnya sebagai pendukung penelitian yang dibuat dalam lembar observasi lapangan.

\section{Studi Dokumenter}

Studi dokumenter dilakukan untuk pengambilan data-data yang dibutuhkan dari beberapa instansi-instansi yang terkait yaitu peta administrasi. Instansi yang terkait dengan data-data tersebut, yaitu Dinas Pekerjaan Umum (PU) Kabupaten Karo, Dinas Kehutanan Kabupaten Karo, Badan Perencanaan Pembangunan Daerah (BAPPEDA) Kabupaten Karo, dan Badan Penanggulangan Bencana Daerah (BPBD) Kabupaten Karo.

\section{Variabel Penelitian}

Variabel yang digunakan dalam penelitian ini ialah debit aliran sungai, lebar sungai, tinggi tebing, lebar tebing, dan gradien sungai. Metode pengukuran variabel dalam penelitian ini disajikan dalam Tabel 1.

Tabel 1. Variabel Penelitian

\begin{tabular}{|c|c|c|c|}
\hline Parameter & Variabel & Skala Data & $\begin{array}{c}\text { Metode Pengukuran } \\
\text { Variabel }\end{array}$ \\
\hline \multirow{12}{*}{$\begin{array}{l}\text { Morfologi } \\
\text { Sungai }\end{array}$} & \multirow{3}{*}{\begin{tabular}{lc}
\multicolumn{2}{l}{ Debit Aliran Sungai } \\
$-\quad$ Kecepatan Aliran \\
$-\quad$ Luas Penampang
\end{tabular}} & \multirow[t]{3}{*}{ Rasio } & Observasi Lapangan \\
\hline & & & Data Sekunder \\
\hline & & & Rumus Perhitungan \\
\hline & \multirow[t]{2}{*}{ Tinggi Tebing } & \multirow[t]{2}{*}{ Rasio } & Observasi Lapangan \\
\hline & & & Data Sekunder \\
\hline & \multirow[t]{2}{*}{ Lebar Tebing } & \multirow[t]{2}{*}{ Rasio } & Observasi Lapangan \\
\hline & & & Data Sekunder \\
\hline & \multirow[t]{3}{*}{ Gradien Sungai } & \multirow[t]{3}{*}{ Rasio } & Observasi Lapangan \\
\hline & & & Data Sekunder \\
\hline & & & Rumus Perhitungan \\
\hline & \multirow[t]{2}{*}{ Lebar Sungai } & \multirow[t]{2}{*}{ Rasio } & Observasi Lapangan \\
\hline & & & Data Sekunder \\
\hline
\end{tabular}

Sumber: Pengolahan Data, 2016

\section{Persiapan penelitian}

Pada tahap persiapan yang harus dilakukan adalah mengumpulkan data dan referensi untuk mendukung penelitian ini disajikan pada Tabel 2.

Tabel 2. Data Penelitian

\begin{tabular}{|c|c|c|}
\hline No. & Nama Bahan & Fungsi \\
\hline 1. & $\begin{array}{ll}\text { Peta } & \text { aliran } \\
\text { sungai } & \end{array}$ & $\begin{array}{l}\text { Mengetahui aliran } \\
\text { Sungai Lau Borus }\end{array}$ \\
\hline 2. & $\begin{array}{l}\text { Jurnal/ buku/ } \\
\text { skripsi }\end{array}$ & $\begin{array}{l}\text { Menjadi bahan } \\
\text { referensi }\end{array}$ \\
\hline
\end{tabular}

\section{Pelaksanaan Penelitian}

Pada tahap ini dilakukan survey lapangan dengan melakukan observasi langsung yakni menetapkan sampel, melakukan pengukuran, dan mencatat hasil pengukuran menggunakan panduan lembar observasi. Pengukuran yang dilakukan adalah sebagai berikut:

1. Pengukuran debit aliran sungai menggunakan metode pelampung.

2. Pengukuran tinggi tebing dan lebar tebing menggunakan meteran. 
3. Pengukuran gradien sungai diperoleh dari data tinggi hulu, hilir sungai, panjang sungai dan diolah dalam rumus dan menggunakan GPS.

4. Pengukuran menggunakan lembar observasi.
Gambaran prosedur penelitian yang akan dilaksanaan selengkapnya ditunjukkan pada Gambar 3.

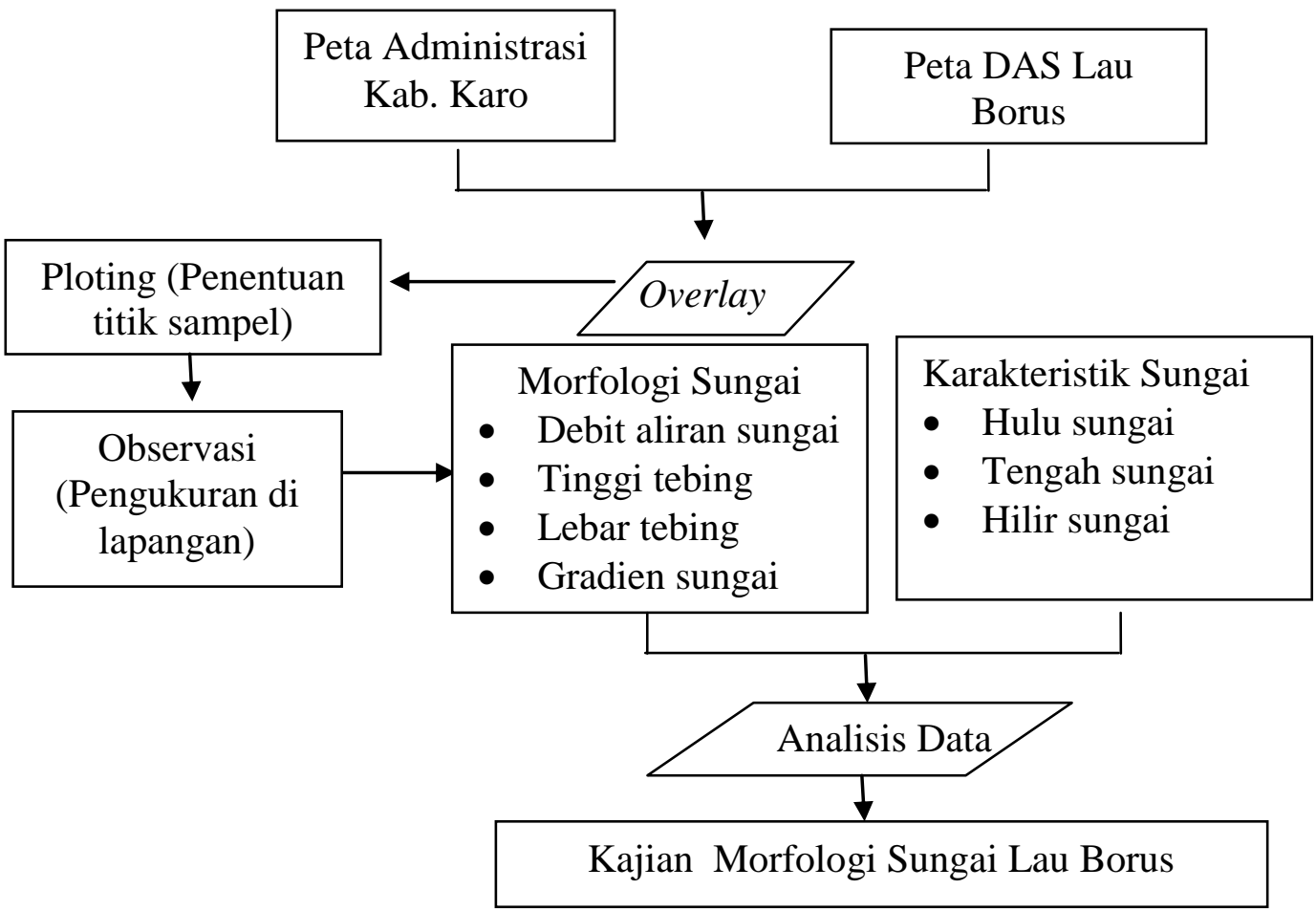

Gambar 3. Skema Prosedur Penelitian

\section{Teknik Analisis Data}

Teknik analisis data yang dipergunakan peneliti dalam penelitian ini adalah teknik analisis deskriptif kualitatif yakni data-data yang diperoleh dari hasil pengukuran lapangan yaitu debit air sungai, tinggi tebing, lebar tebing, lebar sungai, dan gradient sungai. karakteristi sungai diketahui setelah menganalisis keadaan morfologi Sungai Lau Borus di bagian hulu, bagian tengah, dan bagian hilir sungai. Data debit air Sungai Lau Borus setelah dilewati aliran lahar dingin tahun 2016 diperoleh dengan rumus:

$$
\mathrm{Q}=\mathrm{V} \times \mathrm{A}
$$

Keterangan:

$\mathrm{Q}=$ Debit air $\left(\mathrm{m}^{3} / \mathrm{s}\right)$

$\mathrm{V}=$ Kecepatan aliran $(\mathrm{m} / \mathrm{s})$

$\mathrm{A}=$ Luas penampang basah $\left(\mathrm{m}^{2}\right)$
Kecepatan aliran sungai diketahui melalui pengukuran di lapangan untuk dihitung dengan rumus:

$$
\mathrm{V}=\mathrm{D} / \mathrm{t}
$$

Keterangan:

$\mathrm{V}=$ Kecepatan aliran $(\mathrm{m} / \mathrm{s})$

$D=$ Jarak penampang I \& II (m)

$\mathrm{t}=$ Waktu menempuh jarak $(\mathrm{s})$

Luas penampang sungai diketahui melalui pengukuran di lapangan untuk dihitung dengan rumus:

$$
A=L \times d
$$

Keterangan:

$A=$ Luas penampang basah $\left(\mathrm{m}^{2}\right)$

$\mathrm{L}=$ Lebar saluran $(\mathrm{m})$

$\mathrm{D}=$ Kedalaman air rata-rata $(\mathrm{m})$

Data tinggi tebing sungai dan lebar tebing Sungai Lau Borus setelah dilewati aliran lahar dingin tahun 2016 diperoleh 
dengan melakukan pengukuran langsung ke lapangan. Data gradien Sungai Lau Borus setelah dilewati aliran lahar dingin tahun 2016 diperoleh dengan rumus:

Keterangan:

$$
S=\frac{H}{L} \times 100 \%
$$

$S=$ Kemiringan dasar sungai (\%)

$\mathrm{H}=$ Beda tinggi antara elevasi hulu dan hilir sungai $(m)$

$\mathrm{L} \quad=$ Panjang sungai $(\mathrm{km})$

Data lebar sungai diperoleh setelah dilakukan pengukuran melalui citra dan pengukuran langsung di lapangan. Data yang diperoleh kemudian diolah dandianalisis sehingga dapat memberikan gambaran keadaan morfologi sungai dan karaktersitik sungaiyang diteliti. Data dideskripsikan berdasarkan pengukuran lapangan setelah dialiri aliran lahar dingin untuk mengidentifikasi dampak secara keseluruhan dari aliran lahar dingin terhadap Sungai Lau Borus dan karaktersitik Sungai Lau Borus setelah dialiri aliran lahar dingin.

Karakteristik sungai diperoleh setelah diketahui keadaan morfologi sungai di bagian hulu sungai, bagian tengah sungai, dan bagian hilir sungai. Karakteristik sungai di hulu dicirikan dengan sungai yang dalam, erosi tegak, letak sungai curam, dan daya angkut material yang besar. Karakteristik sungai bagian tengah dicirikan dengan pengurangan kecepatan aliran air, daya angkut material kurang, dan keseimbangan erosi dengan sedimentasi. Karakteristik hilir dicirikan dengan ketinggian sungai rendah, tidak terjadi erosi tegak, daya angkut berkurang, dan tingkat sedimentasi tinggi.

\section{HASIL DAN PEMBAHASAN \\ Dampak Lahar Dingin Terhadap Morfologi Sungai Lau Borus \\ Penelitian ini dilaksanakan di aliran} Sungai Lau Borus, Kabupaten Karo dengan sampel aliran Sungai Lau Borus. Sampel penelitian yang di survey kelapangan merupakan sampel yang dapat dijangkau peneliti dan diizinkan masuk oleh petugas penjagaan zona berbahaya Gunungapi Sinabung. Beberapa daerah titik sampel yang telah ditentukan merupakan zona berbahaya Gunungapi Sinabung dan telah tertimbun material vulkanik. Akses menuju desa yang merupakan aliran Sungai Lau Borus di kaki Gunungapi Sinabung sulit dijangkau. Berdasarkan survei lapangan yang telah dilakukan pada 19 titik sampel yang tersebar di aliran Sungai Lau Borus, maka diperoleh data keadaan morfologi Sungai Lau Borus pasca erupsi Gunungapi Sinabung Tahun 2016. Data survey penelitian yang diperoleh yaitu koordinat titik sampel, tinggi tebing sungai, lebar tebing sungai, lebar sungai, elevasi di hulu, elevasi di hilir, dan debit air sungai yang diteliti pada Juli 2016.

Data hasil penelitian bertujuan untuk menjawab dan mencapai tujuan dari penelitian yaitu mengetahui morfologi Sungai Lau Borus dan karakteristik Sungai Lau Borus setelah dilewati aliran lahar dingin.

Sungai Lau Borus merupakan salah satu sungai yang mengalir dari Danau Lau Kawar menuju ke Sungai Lau Cimba, Kabupaten Karo dengan panjang aliran Sungai Lau Borus adalah $32,5 \mathrm{~km}$. Sungai Lau Borus merupakan jalur lahar dingin Gunung Sinabung karena daerah alirannya melewati kaki Gunung Sinabung. Hasil erupsi Gunung Sinabung berupa material batu, debu dan pasir dibawa menuju Sungai Lau Borus oleh air hujan. Hasil erupsi yang berupa material pasir, debu, dan batu yang dibawa air hujan menuju ke Sungai Lau Borus menyebabkan terjadinya erosi dan sedimentasi saluran air sungai.

Kondisi morfologi Sungai Lau Borus juga dipengaruhi oleh hilangnya hutan di pinggir aliran sungai. Hilangnya hutan di pinggir sungai menyebabkan cadangan air tanah sebagai sumber air sungai semakin berkurang dan lereng yang curam mengalami erosi. Hutan terbakar oleh aliran lahar dan tertimbun lontaran material vulkanik yang berasal dari letusan. Keadaan morfologi sungai yang diamati 
ialah debit air sungai, tinggi tebing sungai, lebar tebing sungai, dan gradien sungai.

Keadaan Sungai Lau Borus setelah dialiri lahar dingin diketahui dengan melakukan pengukuran ke aliran Sungai Lau Borus. Berdasarkan hasil pengukuran morfologi sungai diperoleh data titik koordinat titik sampel, debit air sungai, tinggi tebing, lebar tebing, lebar sungai, dan gradien sungai pasca erupsi Gunungapi Sinabung Tahun 2016.

\section{Aliran Sungai Lau Borus di Desa Kuta Gugung}

Secara astronomis titik pengamatan aliran Sungai Lau Borus di Desa Kuta Gugung terletak pada $3^{\circ} 11^{\prime} 54,47^{\prime \prime} \mathrm{LU}$, $98^{\circ} 23^{\prime} 52,83^{\prime \prime} B \mathrm{TT}$ dan secara administrasi berada di Kecamatan Namanteran, Kabupaten Karo. Titik ini ialah Danau Lau Kawar yang merupakan hulu Sungai Lau Borus. Danau Lau Kawar tidak dialiri lahar dingin karena posisinya tidak berada di arah letusan Gunungapi.

Debit aliran Sungai Lau Borus dititik ini ialah $1,46 \mathrm{~m}^{3} / \mathrm{s}$. Lebar tebing sebelah kanan ialah 2,13 $\mathrm{m}$ dan sebelah kiri 4,75 $\mathrm{m}$. Tinggi tebing sebelah kanan ialah 0,52 $\mathrm{m}$ dan sebelah kiri 1,87 m. Danau Lau Kawar berada di ketinggian 1445 mdpl. Lebar Sungai Lau Borus yang ialah 7,75 m. Gradien Sungai Lau Borus ialah 2,4\% dari hulu hingga ke hilir.

\section{Aliran Sungai di Desa Sigarang-garang}

Secara astronomis titik pengamatan aliran Sungai Lau Borus di Desa Sigaranggarang terletak pada $3^{\circ} 11^{\prime} 25,76 \mathrm{LU}$, $98^{\circ} 24^{\prime} 42,73^{\prime \prime} B T$ dan secara administrasi berada di Kecamatan Namanteran, Kabupaten Karo. Titik ini berada dekat dengan pemukiman masyarakat dan mengalami perubahan morfologi akibat lahar dingin Gunungapi Sinabung.

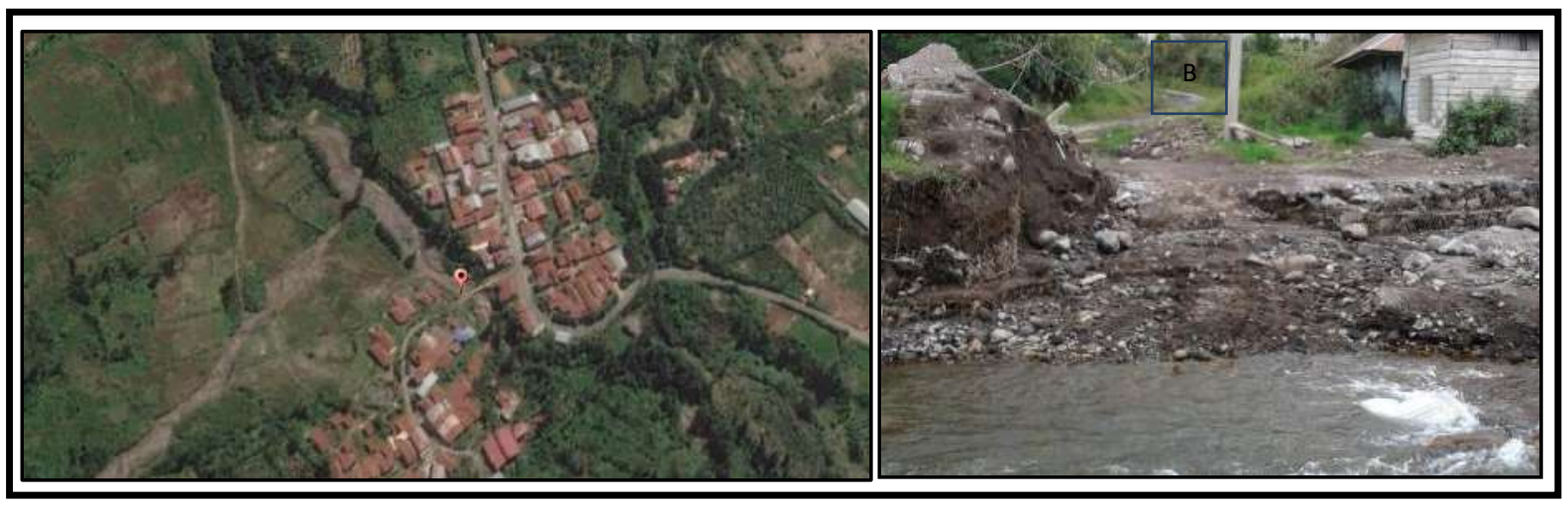

Gambar 4. Morfologi Sungai Lau Borus (A) Citra Morfologi Sungai Di Titik Sampel $3^{\circ} 11 ' 25,76 " \mathrm{LU}, 98^{\circ} 24^{\prime} 42,73^{\prime \prime B T ;}$ (B) Morfologi Sungai Di Desa Sigarang-garang 1, Kecamatan Namanteran, Kabupaten Karo (Sumber: Google Earth, 2016; Dokumentasi Penelitian, 2016)

Debit air di Sungai Lau Borus ialah $5,87 \mathrm{~m}^{3} / \mathrm{s}$. Lebar tebing sebelah kanan ialah $2 \mathrm{~m}$ dan sebelah kiri 3,78 $\mathrm{m}$. Tinggi tebing sebelah kanan ialah 1,12 $\mathrm{m}$ dan sebelah kiri 1,3 m. Titik ini berada di ketinggian 1335 mdpl. Lebar Sungai Lau Borus yang ialah 2,19 m. Gradien Sungai Lau Borus ialah 2,4\% dari hulu hingga ke hilir. Kondisi fisik air berwarna coklat karena terpengaruh aliran lahar dingin yang berasal dari sumber mata air yang teraliri aliran lahar dingin.

\section{Aliran Sungai di Desa Guru Kinayan}

Secara astronomis titik pengamatan aliran Sungai Lau Borus di Desa Guru Kinayan terletak pada $3^{\circ} 7^{\prime} 43,58^{\prime \prime} \mathrm{LU}$, 98²3'55,75"BT berada di Desa Guru Kinayan, Kecamatan Payung, Kabupaten Karo. Titik ini mengalami dilewati olehlahar dingin Gunungapi Sinabung dan berada di kaki Gunung Sinabung. Aliran 
sungai pada titik ini terdapat banyak batu, pasir dan debu. Debit air dipengaruhi batuan yang berada di aliran sungai sehingga menimbulkan jeram yang mempengaruhi besarnya debit air.

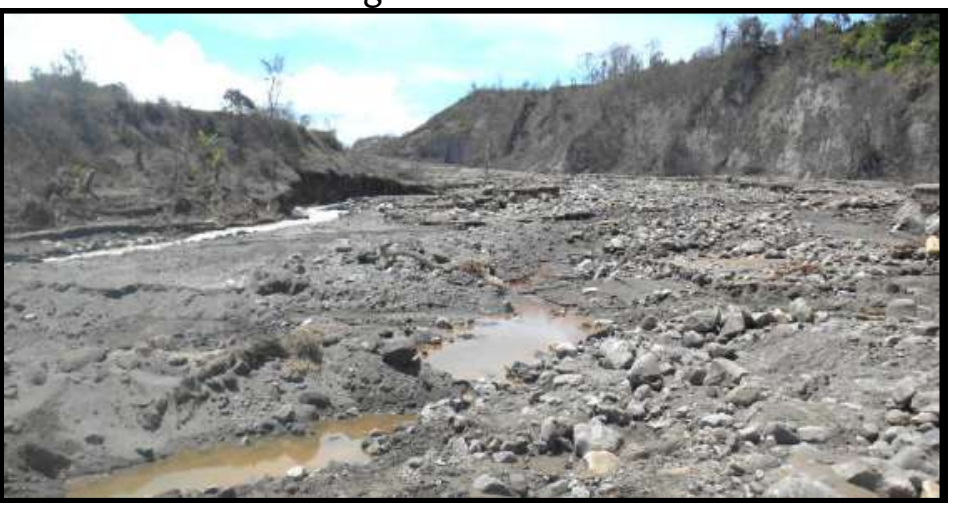

Gambar 5. Morfologi Sungai Di Desa Guru Kinayan 1, Kecamatan Payung, Kabupaten Karo (Sumber: Google Earth, 2016; Dokumentasi Penelitian, 2016)

Debit air di Sungai Lau Borus ialah 3,76 $\mathrm{m}^{3} / \mathrm{s}$. Lebar tebing sebelah kanan ialah 0,3 $\mathrm{m}$ dan sebelah kiri 10,3 $\mathrm{m}$. Tinggi tebing sebelah kanan ialah $1,95 \mathrm{~m}$ dan sebelah kiri $1,8 \mathrm{~m}$. Titik ini berada di ketinggian 986 mdpl. Lebar Sungai Lau Borus yang ialah $108,24 \mathrm{~m}$. Gradien Sungai Lau Borus ialah 2,4\% dari hulu hingga ke hilir. Kondisi fisik air berwarna coklat karena terpengaruh aliran lahar dingin yang berasal dari sumber mata air yang teraliri aliran lahar dingin.

\section{4. $\quad$ Aliran Sungai di Desa Payung}

Secara astronomis titik pengamatan aliran Sungai Lau Borus di Desa Payung terletak pada $3^{\circ} 7^{\prime} 41,24 " \mathrm{LU}$, $98^{\circ} 22^{\prime} 58,05^{\prime \prime} B T$ dan secara administrasi berada di Desa Payung, Kecamatan Payung, Kabupaten Karo. Titik ini merupakan aliran lahar dingin Gunungapi Sinabung. Debit air dipengaruhi batuan yang berada di aliran sungai sehingga menimbulkan jeram yang mempengaruhi besarnya debit air. Sedimentasi terjadi di aliran yang berkelok dan menyebabkan aliran sungai bercabang membentuk anyaman.

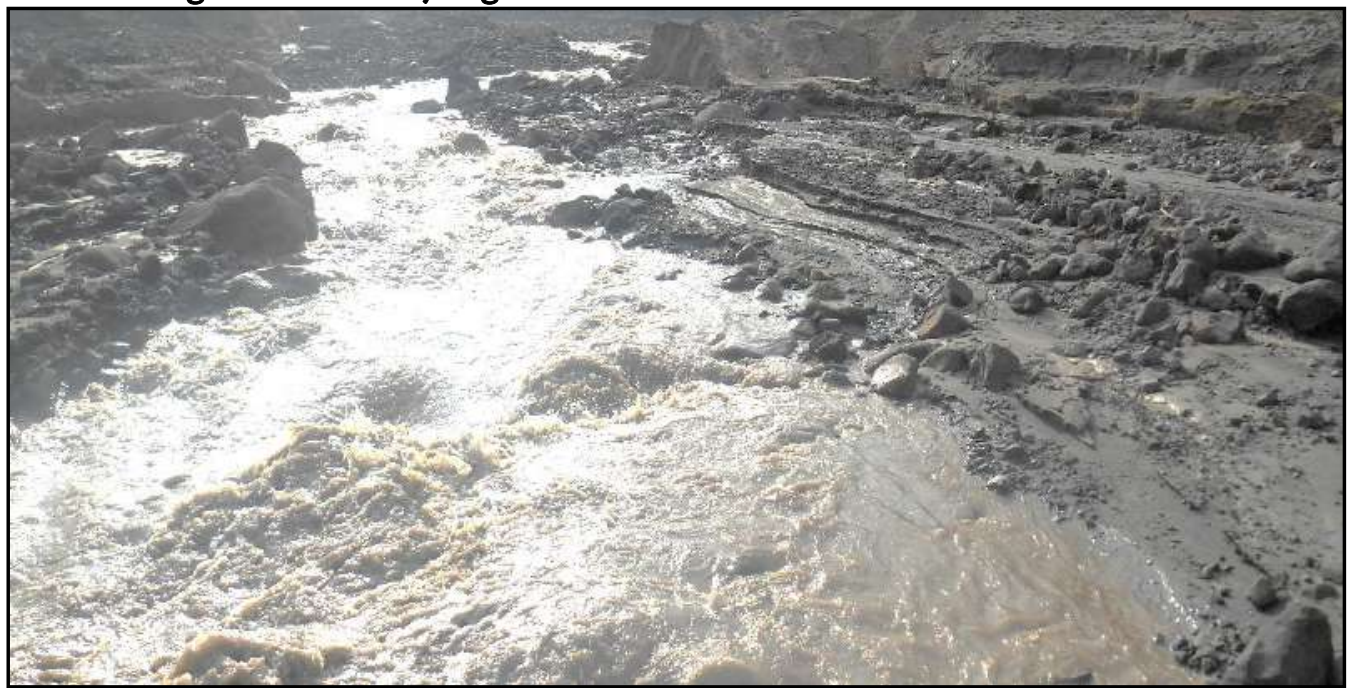

Gambar 6. Morfologi Sungai Di Desa Payung 1, Kecamatan Payung, Kabupaten Karo (Sumber: Google Earth, 2016; Dokumentasi Penelitian, 2016)

Debit air di Sungai Lau Borus ialah $2,24 \mathrm{~m}^{3} / \mathrm{s}$. Lebar tebing sebelah kanan ialah
$5,23 \mathrm{~m}$ dan sebelah kiri 12,81 $\mathrm{m}$. Tinggi tebing sebelah kanan ialah $1,15 \mathrm{~m}$ dan 
sebelah kiri 1,08 m. Titik ini berada di ketinggian 918 mdpl. Lebar Sungai Lau Borus yang ialah $156,58 \mathrm{~m}$. Gradien Sungai Lau Borus ialah 2,4\% dari hulu hingga ke hilir. Kondisi fisik air berwarna coklat karena terpengaruh aliran lahar dingin yang berasal dari sumber mata air yang teraliri aliran lahar dingin.

\section{Aliran Sungai di Desa Tanjung Merawa}

Secara astronomis titik pengamatan aliran Sungai Lau Borus di Desa Tanjung Merawa terletak pada $3^{\circ} 7^{\prime} 44,94 " \mathrm{LU}$, 98²1'38,08"BTdan secara administrasi berada di Kecamatan Tiganderket, Kabupaten Karo. Titik ini merupakan aliran lahar dingin Gunungapi Sinabung. Debit air di Sungai Lau Borus ialah $2,81 \mathrm{~m}^{3} / \mathrm{s}$. Lebar tebing sebelah kanan ialah $5,25 \mathrm{~m}$ dan sebelah kiri $36,15 \mathrm{~m}$. Tinggi tebing sebelah kanan ialah 1,14 $\mathrm{m}$ dan sebelah kiri 1,09 m. Titik ini berada di ketinggian 916 mdpl. Lebar Sungai Lau Borus yang ialah 51,90 m. Gradien Sungai Lau Borus ialah 2,4\% dari hulu hingga ke hilir. Kondisi fisik air berwarna coklat karena terpengaruh aliran lahar dingin yang berasal dari sumber mata air yang teraliri aliran lahar dingin. Sisi tebing sungai telah dibangun pelindung agar banjir lahar tidak merendam perkebunan serta rumah penduduk yang berada di pinggir Sungai Lau Borus.

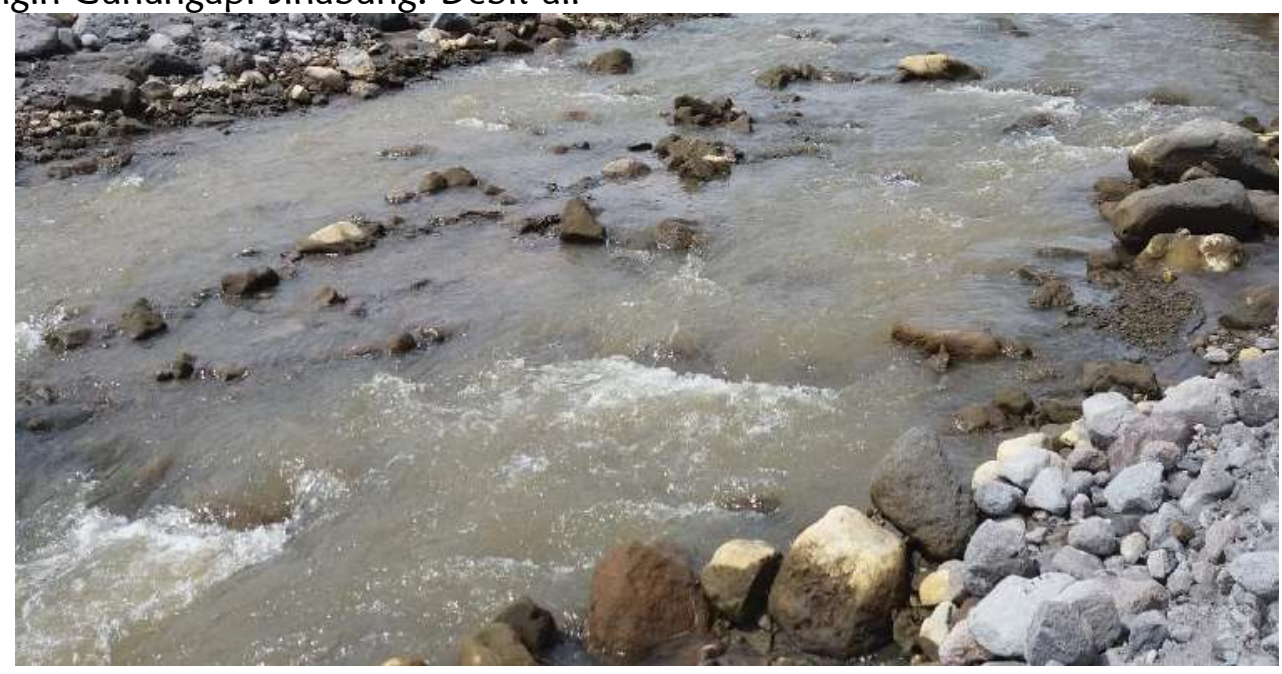

Gambar 7. Morfologi Sungai Di Desa Tanjung Merawa, Kecamatan Tiganderket, Kabupaten Karo (Sumber: Google Earth, 2016; Dokumentasi Penelitian, 2016)

\section{Aliran Sungai di Desa Jandi Meriah}

Secara astronomis titik pengamatan aliran Sungai Lau Borus di Desa Jandi Meriah terletak pada $3^{\circ} 7^{\prime} 38,66 " \mathrm{LU}$, 98¹9'43,78"BTdan secara administrasi berada di Kecamatan Tiganderket, Kabupaten Karo. Titik ini merupakan aliran lahar dingin Gunungapi Sinabung. Debit air di Sungai Lau Borus ialah $6,46 \mathrm{~m}^{3} / \mathrm{s}$. Lebar tebing sebelah kanan ialah $46,36 \mathrm{~m}$ dan sebelah kiri $1,94 \mathrm{~m}$. Tinggi tebing sebelah kanan ialah 1,52 m dan sebelah kiri 1,3 m. Titik ini berada di ketinggian 727 mdpl. Lebar Sungai Lau Borus yang ialah 60,65 m. Gradien Sungai Lau Borus ialah 2,4\% dari hulu hingga ke hilir. Kondisi fisik air berwarna coklat karena terpengaruh aliran lahar dingin yang berasal dari aliran Sungai Lau Borus yang teraliri aliran lahar dingin.

\section{Karaktersitik Sungai Lau Borus}

1. Sungai Bagian Hulu

Hulu Sungai Lau Borus terletak di kaki Gunung Sinabung yang bersumber dari Danau Lau Kawar di Desa Kuta Gugung, Kecamatan Namanteran, Kabupaten Karo. Intensitas air menyebabkan erosi karena kemiringan sungai yang berasal dari danau menuju ke aliran sungai dan menyebabkan sungai tidak dalam. Kondisi dasar sungai umumnya berbatu dan berpasir yang 
berasal dari hasil letusan Gunung Sinabung dan hasil rekahan mataair pegunungan. Lebar tebing umumnya $1 \mathrm{~m}-4 \mathrm{~m}$ karena tidak terjadi proses sedimentasi yang besar. Tebing sungai ditumbuhi rumput dan pohon sebagai penyimpan cadangan air sungai. Kondisi fisik air sungai tidak berwarna dan tidak berbau karena tidak teraliri aliran lahar dingin. Debit air sungai ialah $1,46 \mathrm{~m}^{3} / \mathrm{s}-5,29 \mathrm{~m}^{3} / \mathrm{s}$. Tinggi tebing sungai ialah $0,52 \mathrm{~m}-1,87 \mathrm{~m}$. Lebar sungai ialah 7,01 m -7,75 m.

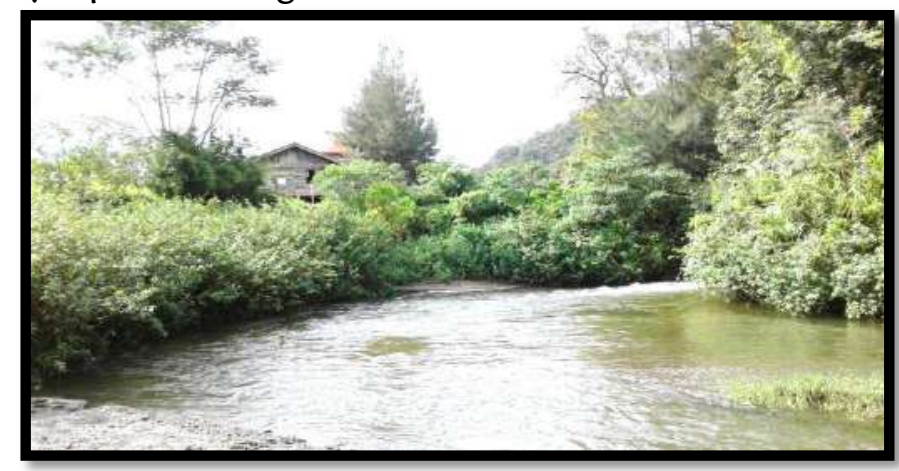

Gambar 8. Hulu Sungai Lau Borus di Desa Kutagugung, Kecamatan Namanteran, Kabupaten Karo (Sumber: Dokumentasi Penelitian, 2016)

Daerah bagian hulu di Desa Sigarang-garang dialiri oleh aliran lahar dingin. Lebar tebing sungai 2-14 meter karena terjadi proses sedimentasi akibat hasil erupsi Gunungapi Sinabung terbawa aliran lahar dingin. $\mathrm{Di}$ tebing sungai terdapat banyak batu, pasir dan batang pohon yang terbawa lahar dingin. Kondisi fisik air berwarna coklat keabu-abuan dan berbau belerang. Debit air sungai ialah 1,89 $\mathrm{m}-5,87 \mathrm{~m}$. Tinggi tebing ialah 1,12 $\mathrm{m}-1,68$ m. Lebar sungai ialah $2,19 \mathrm{~m}-18,3 \mathrm{~m}$.

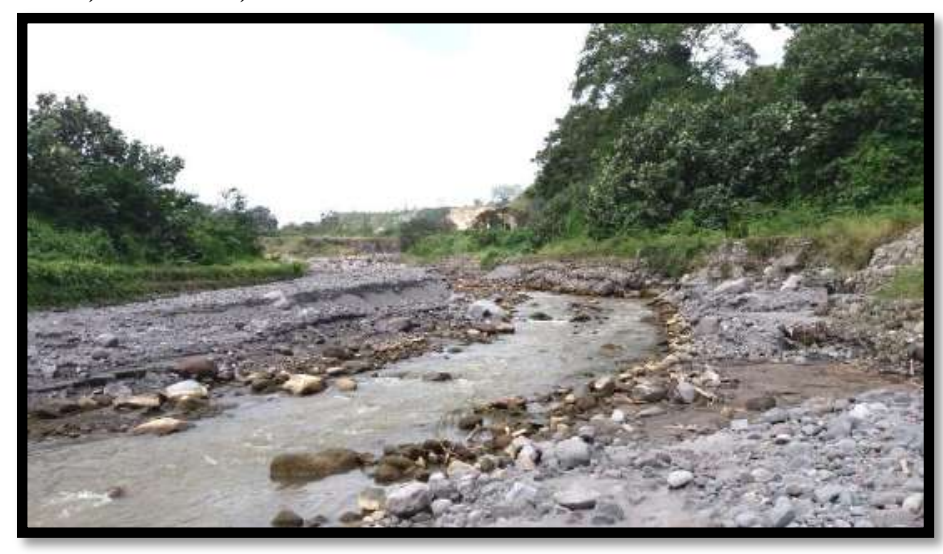

Gambar 9. Hulu Sungai Lau Borus di Desa Guru Kinayan,

Kecamatan Payung, Kabupaten Karo (Sumber: Dokumentasi Penelitian, 2016)

Lebar tebing Sungai Lau Borus ialah 0,3 m -36,15 mkarena penumpukan material hasil erupsi Gunung Sinabung yang dibawa melalui aliran lahar dingin ke tebing sungai. Debit sungai ialah $1,82 \mathrm{~m}^{3} / \mathrm{s}$
2. Sungai Bagian Tengah

Bagian tengah Sungai Lau Borus terletak di kaki Gunung Sinabung yang terletak di Desa Guru Kinayan, Kecamatan Payung, Kabupaten Karo. Aliran air yang tidak deras karena penampang sungai yang relatif landai. Proses mengalirnya air menyebabkan proses transportasi material sungai dibawa dari hulu ke bagian tengah aliran Sungai Lau Borus. $\mathrm{m}$. Lebar sungai ialah $9,16 \mathrm{~m}-156,58 \mathrm{~m}$. Kondisi dasar sungai umumnya berbatu dan berpasir yang berasal dari hasil letusan Gunung Sinabung dan batuan yang dibawa dari hulu sungai. Kondisi fisik air sungai 
berwarna coklat keabu-abuan dan berbau belerang.

\section{Sungai Bagian Hilir}

Bagian hilir Sungai Lau Borus terletak di Desa Jandi meriah, Kecamatan Tiganderket, Kabupaten Karo. Aliran di bagian hilir Sungai Lau Borus alirannya tidak deras seperti di hulu. Aliran air yang tidak deras karena penampang sungai yang relatif landai. Proses mengalirnya air menyebabkan proses trasportasi material sungai dibawa dari hulu ke bagian tengah aliran Sungai Lau Borus.

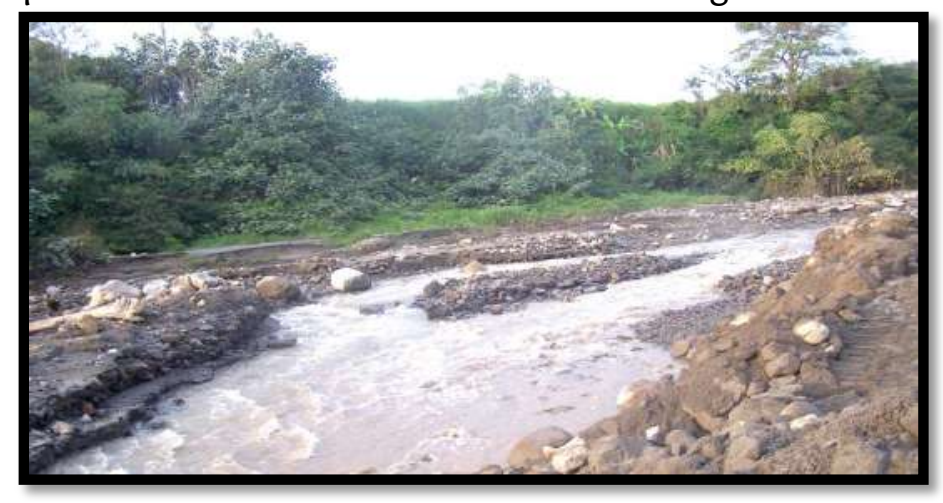

Gambar 10. Hilir Sungai Lau Borus di Desa Jandi Meriah,

Kecamatan Payung, Kabupaten Karo

Lebar tebing Sungai Lau Borus ialah 1,05-46,36 meter karena tersedimentasi material hasil erupsi Gunung Sinabung yang dibawa melalui aliran lahar dingin dan tererosi karena banjir lahar dingin. Erosi yang terus terjadi menyebabkan saluran Sungai Lau Borus semakin lebar. Lebar sungai di hilir ialah 22,16 m -60,65 $\mathrm{m}$. Debit air sungai ialah $2,16 \mathrm{~m}^{3} / \mathrm{s}$ $6,49 \mathrm{~m}^{3} / \mathrm{s}$. Tinggi tanggul sungai ialah $1,1 \mathrm{~m}$ $-1,87 \mathrm{~m}$. Kondisi dasar sungai umumnya berbatu dan berpasir yang berasal dari hasil letusan Gunung Sinabung dan batuan yang dibawa dari hulu sungai. Kondisi fisik air sungai berwarna coklat keabu-abuan dan berbau belerang.

\section{KESIMPULAN DAN SARAN \\ Kesimpulan}

Berdasarkan hasil penelitian dan pembahasan yang telah dilakukan maka dapat ditarik kesimpulan sebagai berikut:

1. Aliran lahar dingin pasca erupsi Gunung Sinabung (2016) yang mengalir menuju Sungai Lau Borus memiliki dampak terhadap morfologi Sungai Lau Borus. Kemiringan Sungai Lau Borus adalah $2,4 \%$ dengan panjang sungai $32,5 \mathrm{~km}$. Tinggi tebing sebelah kanan sungai adalah $0,52-2,71 \mathrm{~m}$. Tinggi tebing sungai sebelah kiri adalah 1,06 - 3,17. Lebar tebing sungai sebelah kanan adalah 0,3 - 46,36 m. Lebar tebing sebelah kiri adalah 1,08 - 36,15 m. Debit aliran Sungai Lau Borus adalah $3,84 \mathrm{~m}^{3} / \mathrm{s}$. Lebar sungai adalah $7,01-$ $156,58 \mathrm{~m}$.

2. Karakteristik Sungai Lau Borus setelah teraliri aliran lahar dingin pasca erupsi Gunung Sinabung menimbulkan dampak terhadap morfologi sungai. Bagian hulu sungai yang berada di Danau Lau Kawar tidak mengalami perubahan karena tidak teraliri aliran lahar dingin. Bagian tengah sungai yang berada di Desa Guru Kinayan terkena dampak karena aliran sungai yang berada di kaki Gunung Sinabung. Bagian hilir sungai mengalami proses sedimentasi hasil letusan Gunung Sinabung akibat aliran lahar dingin yang juga mengubah kondisi fisik air.

Saran

Berdasarkan kesimpulan yang telah dikemukakan di atas disarankan beberapa hal sebagai berikut:

1. Bagi Pemerintah Kabupaten Karo memerlukan strategi mitigasi untuk meminimalisir bencana lahar dingin, seperti membangun sabo untuk 
meminimalkan tingkat sedimentasi disungai, tebing pengaman tebing sungai agar tidak terus terjadi erosi, dan pos pemantau khusus yang permanen agar pengelolaan keadaan morfologinya dapat terus dipantau.

2. Bagi peneliti selanjutnya yang ingin melakukan penelitian yang sejenis, agar melakukan persiapan dan perencanaan yang maksimal, sehingga diharapkan dapat melaksanakan penelitian secara maksimal.

\section{DAFTAR PUSTAKA}

Aisyah., Purnamawati., 2012, Tinjauan Dampak Banjir Lahar Kali Putih, Kabupaten Magelang Pasca Erupsi Merapi 2010, Jurnal Teknologi Technoscientia, Vol. 5 No. 1 Agustus 2012.

Asdak., 2002, Hidrologi Dan Pengelolaan Daerah Aliran Sungai, Gajah Mada University Press, Yogyakarta.

Astuti, A. J. D., \& Berutu, N. (2012). Studi Mengenai Koefisien Aliran Sebagai Indikator Kerusakan Lingkungan $\mathrm{Di}$ Daerah Aliran Sungai Deli. JURNAL GEOGRAFI, 4(1), 1-14.

Bahri, Perdi., 2013, Dampak Banjir Lahar Dingin Pasca Erupsi Merapi 2010 di Kali Gendol, Universitas Sebelas Maret, Surakarta.

Bappeda, 2014, Profil Daerah Tahun 2014, Pemerintah Kabupaten Karo, Karo.

BWS., 2015, Detail DesainPengendalian Lahar Gunung Sinabung Kabupaten Karo, Balai Wilayah Sungai Sumatera II, Medan.

Bronto., 2006, Fasies Gunungapi Dan Aplikasinya, Jurnal Geologi Indonesia, Vol. 1 No. 2 Juni 2006: 59-71.

Bumi, Jurnal., 2015, Mengenal Tipe-Tipe Daerah Aliran Sungai, https://jurnalbumi.com/daerah- aliran-sungai/ (diakses pukul 07:25, 7 April 2016)

Dipayana, Gilang Arya., 2013, Dampak Banjir Lahar Dingin Pasca Erupsi Merapi 2010 di Kali Gendol, Universitas Gajah Mada, Yogyakarta.

Hadmoko.,2015, Banjir Lahar,GadjahMada University Press, Yogyakarta.

Hidayat., 2012, Mekanika Fluida Dan Hidrolika, Universitas Mercu Buana, Jakarta.

Kehutanan., 2010, Pembagian DAS Wilayah Kabupaten Karo, Pemerintah Kabupaten Karo, Karo.

Kodoatie., Sjarief., 2010, Tata Ruang Air, Yogyakarta, Penerbit Andi.

Kusumosubroto., 2013, Aliran Debris \& Lahar, Graha Ilmu, Yogyakarta.

Mantra, Ida Bagoes., 2009, Demografi Umum, Pustaka Pelajar, Yogyakarta.

Mardiyanah., 2005, Evaluasi Kemampuan Lahan Di Wilayah Kecamatan Karanganyar Kabupaten Pekalongan, Karya Tulis IImiah, Universitas Negeri Semarang.

Marfai., 2012, Sejarah Letusan Gunung Merapi Berdasarkan Fasies Gunungapi di Daerah Istimewa Yogyakarta, Riset Geologi dan Pertambangan, Vol. 22 No. 2 Juni 2012: 73-79.

Nuryanto., 2002, Analisis Debit Aliran Pada Sungai Alluvial, Thesis, Universitas Diponegoro.

Peraturan Pemerintah Republik Indonesia (PP) Nomor 38 Tahun 2011 tentang Sungai.

Sari., Nugroho., 2001, Pemanfaatan Pemodelan Aliran Lahar Untuk Pemetaan Kawasan Rawan Bencana Gunungapi Menggunakan Sistem 
Informasi Geografik, Seminar Nasional Pusat SIC Dan Penginderaan Jauh LP-ITS, Surabaya.

Silalahi., 2009, Metode Penelitian Sosial, Reflika Aditama, Bandung.

Soewarno., 2013, Hidrometri Dan Aplikasi Teknosabo Dalam Pengelolaan Sumber Daya Air, Graha Ilmu, Yogyakarta.

Solikha., 2012, Perubahan Morfologi Sungai Code Akibat Aliran Lahar Pasca Erupsi Gunungapi Merapi Tahun 2010, Jurnal Bumi, Vol. 1 No. 3 Tahun 2012.

Swary., 2012, Tinjauan Dampak Banjir Lahar Kali Putih Kabupaten Magelang Pasca Erusi Merapi 2010, Jurnal Teknologi Technoscientia, Vol. 5 No. 1 Agustus 2012: 19-30.
Takeda., 1982, Hidrologi Untuk Pengairan, Pradnya Paramita, Bandung.

Tjeptjep., 2002, Manajemen Bencana Berbasis Masyarakat, Pusat Vulkanologi Dan Mitigasi Bencana Geologi.

Waryono., 1987, Bentuk Struktur Dan Lingkungan Bio-Fisik Sungai, https://staff.blog.ui.ac.id/tarsoen.war yono/achieves/category/makalahdan-karya-ilmiah(diaksespukul07:59, 20 April 2016)

Wiwoho., 2005, Model Identifikasi Daya Tampung Beban Cemaran Sungai Dengan Qual Study Kasus Sungai Babon, Universitas Diponegoro, Semarang 